\title{
Prácticas publicitarias en lengua extranjera: El caso del español en Camerún
}

\author{
Zacharie Hatolong Boho
}

Recibido: 26/06/2013

Aceptado: 30/04/2014

\section{Resumen}

En el espacio urbano de Camerún diversas voces españolas se usan para designar los comercios, los bares, los restaurantes, los hoteles, etc. De hecho, más allá de la tradicional función comunicativa que desempeña todo código lingüístico, la lengua española sirve de instrumento al servicio de la comunicación publicitaria. Unos recursos lingüísticos, principalmente los adjetivos valorativos, los cuantificadores o los locativos espaciales edifican, junto con ciertos motivos tipográficos y cromáticos, un discurso publicitario bastante persuasivo.

Palabras clave: publicidad; español; lengua extranjera; discurso persuasivo; espacio urbano.

Advertising practices in foreign language:

the case of Spanish language in Cameroon

\begin{abstract}
In urban space of Cameroon, several Spanish words are used in order to name shops, bars, restaurants, hotels, etc. Consequently, in addition to the traditional communicative function that is recognized for every linguistic code, Spanish language acts as an instrument for advertisement communication. Some linguistic resources, notably positive adjectives, quantifiers or spatial locatives, are used for building, altogether with typographic and chromatic gadgets, a persuasive advertisement speech.
\end{abstract}

Keywords: advertisement; Spanish language; foreign language; persuasive speech; urban space.

\section{Introducción}

Caro Almela (2007: 55-82) considera la publicidad como una ciencia en sí, por lo que habla de sus fundamentos epistemológicos y metodológicos; Magariños de Morentin (2001) la clasifica en el universo de las ciencias sociales. Por lo demás, los hay que abordan la publicidad en términos de comunicación, confiriéndole así una precisa orientación epistemológica o un cuadro teórico-conceptual.

La publicidad, más allá de que se la considere o no como una ciencia, es un proceso de comunicación que pone de relieve un conjunto de procedimientos expositivos y persuasivos. La enunciación publicitaria es muy compleja porque en ella participan varios recursos tan lingüísticos como metalingüísticos. Por eso, un mensaje o discurso publicitario que sólo se analiza lingüísticamente no revela todos sus componentes. Tal discurso es, por lo tanto, objeto de un estudio interdisciplinar, por lo que puede ocupar las humanidades o las llamadas ciencias sociales en general. En palabras de Gloria Peña Pérez (2008 : 654), 
[...] el mensaje publicitario constituye un proceso de comunicación de carácter persuasivo en el que el emisor es el que expone los argumentos; el público o destinatario a quien se dirige tiene la función de valorar el mensaje y decidir el acto perlocucionario de estar o de desear estar en posesión del objeto anunciado. Es frecuente que el enunciado en el que se fundamenta el argumento principal se presente como un imperativo, una exhortación o una sugerencia, que lleve al destinatario a responder positivamente a querer usar o a poseer el producto (Lo Cascio 1998: 335-340). Los emisores buscan seducir a los receptores, teniendo en cuenta el perfil del individuo o del grupo social al que se dirija la campaña o el anuncio publicitario concreto (Santiago, 2005: 77).

A partir de las anteriores ideas podemos orientar, por nuestra cuenta, el estudio del mensaje publicitario hacia disciplinas como la lingüística, la pragmática y la semiótica. El corpus que sustenta este estudio se compone de mensajes publicitarios que, tras una observación directa, hemos apuntado y fotografiado en diversos soportes del espacio urbano camerunés. Los datos así recogidos se abordan desde el prisma de las ciencias del lenguaje.

\section{Retórica de la persuasión y funciones del lenguaje publicitario}

Existe una abundante literatura cuyo objeto es el estudio de los mecanismos de persuasión del discurso publicitario. Y es que existe una retórica propia a la publicidad, retórica que le reconocen muchos especialistas del campo, principalmente Fava-Natali (1995: 2):

Ce discours rhétorique est sous-tendu dans la publicité, qui vise à persuader, à convaincre. Pour ce faire, elle s'appuie sur les conditions d'un langage efficace dans lesquelles la rhétorique " est le premier champ du savoir à s'être interrogé systématiquement sur le langage en tant que moyen de communication et d'autre part à avoir proposé des techniques systématiques pour rendre efficace l'action communicante ». Évacuée de l'enseignement officiel depuis le siècle dernier, historiquement considérée comme art de la feinte, la rhétorique est de nos jours utilisée dans la publicité qui s'apparente à ce type de discours, comme outrance volontaire, jeux sur le langage, etc.

En otra ocasión la misma Faya-Natali afirma que todos los anuncios publicitarios pueden ser interpretados en términos de retórica. Estudiar o pretender entender esta retórica implicaría inspirarse en sus técnicas o procedimientos cuyos recursos se enmarcan forzosamente en el lenguaje. Este último se presenta bajo dos formas, la articulada (la lengua en todos sus mecanismos de actuación oral o escrita) y la no articulada que, a su vez, se opera por medio de diversas dimensiones.

En nuestro trabajo, la retórica de la persuasión radica en una materia diversificada que apela a más de una competencia (competencia lingüística, semiótica, pragmática, socio-cultural, etc.). De momento, procuramos enfocar dicha retórica desde el prisma de las funciones del lenguaje (publicitario).

El marco teórico de este apartado son las ideas de Roman Jakobson, desarrolladas en sus Ensayos de lingüistica general (1963). La teoría de las funciones del lenguaje distingue seis elementos o factores necesarios en el proceso de la comunicación: el contexto, el emisor, el receptor, el canal, el código y el mensaje. Según Louis Herbert 
(2011), cada factor es el punto de culminación de una relación (o función) que se halla establecida entre el mensaje y dicho factor. El lenguaje puede, pues, desempeñar una función referencial (o denotativa, cognitiva, representativa, informativa), emotiva (o expresiva), conativa (o incitativa, imperativa, impresiva), fática (o relacional, de contacto), metalingüística (o metasemiótica, dado que existen lenguajes que no son signos lingüísticos) y poética (estética, retórica). Herbert (2011: 64) dirá que «L'analyse des fonctions du langage consiste à stipuler, pour une unité (par exemple, un mot, un texte, une image), une classe ou un type d'unités (par exemple, un genre textuel ou imagique), la présence/absence des fonctions, les caractéristiques de ces fonctions, notamment leurs relations hiérarchiques et les autres relations qu'elles peuvent entretenir entre elles ».

Estas aseveraciones conllevan dos evidencias importantes. Por una parte, nos enseñan que el lenguaje es más abarcador dado que engloba tanto los signos lingüísticos como los no lingüísticos. Por otra, se evidencia que no toda palabra o expresión, no todo texto o toda imagen desempeña al mismo tiempo todas las seis funciones. Puede que en un corpus se den solamente algunas de estas funciones.

Dicho lo anterior, es fundamental para nosotros examinar los impactos (las funciones) de nuestros datos en tanto que forman parte del lenguaje antes de ver cómo la gente se lo representa. Por supuesto, consideramos nuestro objeto de estudio (el corpus) más como lenguaje que como lengua, más como signos en general que como signos exclusivamente lingüísticos. Se trata de un conjunto heterogéneo que se compone de signos lingüísticos (palabras y expresiones), de signos numéricos (números de teléfono y apartados de correos) y de elementos iconográficos (imágenes). Sin embargo, antes de estudiar este conjunto semiótico-lingüístico y de aplicarle el modelo de Jakobson, debemos dejar por sentado que nos hallamos concreta y realmente en situación de comunicación. De antemano, es necesario tener presente que no todas las funciones jakobsonianas se abordarán aquí; sólo se aplicarán las más representativas.

\subsection{La función referencial o representativa}

Para Gutiérrez Araus y otros (2005: 36), «esta función es inherente a todo acto de comunicación: se puede decir que no existe un mensaje absolutamente desprovisto de información; por ello, aunque predomine otra función, la función referencial siempre es el telón del mensaje». Y en nuestro corpus, la función referencial es la más representativa porque los recursos lingüísticos utilizados no son tan elaborados y se reducen a formas mayoritariamente nominales (casi 95\%) que denotan o referencian cosas o hechos. $\mathrm{M}^{\mathrm{a}}$ Amparo Alcina Caudet (1999: 32) dice a este respecto que « las expresiones referenciales son, desde el punto de vista morfosintáctico, sintagmas nominales ».

\subsection{La función apelativa}

Igualmente llamada función conativa, incitativa, imperativa o impresiva, la función apelativa se caracteriza porque el lenguaje se orienta hacia el receptor. Sus recursos lingüísticos son los vocativos, el modo imperativo, las oraciones interrogativas, la utilización deliberada de elementos afectivos, los adjetivos valorativos, los términos 
connotativos y toda la serie de recursos retóricos. Se da en el lenguaje coloquial, es dominante en la publicidad y propaganda política e ideológica en general. Según Khalef (2011: 98):

Cette fonction dont la visée est persuasive indique une stratégie de communication qui convoque souvent l'illusoire, l'imaginaire, le mythique et le merveilleux pour atténuer le poids de la vie pragmatique et capitaliste que l'homme s'est imposé à force d'écarter toute dimension humaine dans l'établissement de ses relations économiques et sociales. Et que ce soit grâce au mot, à l'image ou encore au symbole, le discours publicitaire a pour but de parvenir à influencer le récepteur (le consommateur) et le pousser à acheter une marchandise ou un service donné. Le tout dépend bien sûr de la manière de faire.

Dentro de nuestro corpus, después de la referencial, la función conativa es la más representativa. Se destacan recursos lingüísticos llamativos (Dulce cama, *Buena olor, Buena vista, Estilo femenino, etc.), así como recursos metalingüísticos de índole icónica y cromática. A este último respecto, sobresalen los colores vivos tales como el rojo, el azul, el blanco y el negro que infieren unos efectos visuales de gran impresión.

\subsection{La función poética}

Se habla de la función poética o estética cuando la atención viene centrada en el mensaje; cuando el mensaje habla de sí mismo ya a partir de su forma, ya a causa de su tono estetizante. Esta práctica revela hasta qué punto el ser humano puede ser movilizado por los sentimientos y la sensibilidad propios de la poesía. En efecto, desde el punto de vista de la forma de la expresión o del contenido, ciertos mensajes publicitarios expresan el sueño como locus communis, la evasión como universo del sueño, la belleza en cuanto valor extremo, el mito ligado a la función imaginativa, etc. En nuestro corpus, más de un caso desempeña la función poética; mencionamos por ejemplo La belleza africana, *Angelica dressing, Dulce noche, Dulce cama, Hotel el dorado, Los Angeles, Luz de paz, Restaurant La paloma blanca, Le $Q G$ de la fiesta, Mahou Cinco Estrellas, Valle encantado, etc. Parte de estos ejemplos, que son el objeto del presente trabajo, viene exclusivamente expresado en español. Muchos de ellos constituyen anuncios multilingües (español, francés, inglés, lengua local) y forman mensajes bastante elaborados cuyo estudio desde la vertiente de la publicidad sería más rico si se realizara no sólo teniendo en cuenta la lengua española.

Hemos demostrado que la gente (tanto la instancia emisora como la receptora) se sirve de ese tipo de lenguaje para evadirse de la dificultosa vida real. Aquí, se privilegia la dimensión onírica de la vida humana, por lo que el sueño baja de su cielo, de su imperio del absoluto, de lo irreal, etc. para hacerse real y tangible. En esos mensajes publicitarios, la función poética va borrando el límite existente entre la instancia emisora y la receptora. El mensaje orientado y centrado en sí mismo goza ya de una autonomía referencial a la par que infiere una referencia heteróclita en función de las sensibilidades de la gente implicada en la comunicación publicitaria. 


\section{3. ¿Publicidad diferida o publicidad en tiempo real?}

Reseñando el libro titulado Las palabras en la publicidad (Baños González et al., 2009), Paloma Fernández Fernández (2010: 287) introduce sus propósitos con las palabras siguientes:

En la publicidad hay palabras, esto es un hecho manifiesto. Unas veces se escuchan, otras se leen o vienen a nuestra mente al contemplar unas imágenes. Es un ingrediente de vital importancia en la eficacia de las campañas publicitarias y, sin embargo, su protagonismo queda eclipsado por el predominio de las imágenes en la sociedad actual. En estas circunstancias, resulta relevante que un libro sobre la publicidad se centre en las palabras, en los textos, titulares, eslóganes, denominación de productos.

Sin lugar a dudas, estas reflexiones acerca de la palabra como componente esencial del mensaje publicitario son pertinentes. Sin embargo, no hay palabra que no pertenezca a un sistema lingüístico; y para que se entienda por parte de un individuo, hace falta que éste esté dotado de cierta competencia (lingüística). Eso plantea la problemática de una publicidad en lengua extranjera o desconocida por parte de sus destinatarios. Parece, por una parte, que no existe ninguna publicidad que sea descontextualizada, y que, por otra, haya cierto distanciamiento entre la producción del mensaje publicitario y su percepción. Este distanciamiento consciente hace que, en ciertas circunstancias, se dé una publicidad diferida desde la perspectiva de su entendimiento en cuanto mensaje fundamentado en signos léxico-semánticos. En este sentido, el fenómeno publicitario se halla diferido porque la latencia de reacción (tiempo que ocurre entre la captación del mensaje publicitario y la comprensión-reacción frente a este mensaje) es importante. Por lo demás, puede decirse que no es el mensaje lingüístico (el significado de las palabras constitutivas del mensaje publicitario) el que motiva la reacción de los consumidores sino la lengua en tanto que se ha convertido en un signo visual.

En efecto, podría decirse que en el contexto del público camerunés, una publicidad en lengua extranjera en general, y en lengua española en particular es, por así decirlo, una publicidad sin destinatario. Los únicos potenciales destinatarios de esta publicidad son aquellos que han aprendido la lengua española en la enseñanza secundaria o universitaria. Sin embargo, el número de hispanohablantes se estimó en unos 7000 en 2005 (Godínez González et al., 2005: 63-69), fecha que no está lejos del periodo de encuesta de este estudio (2007-2009). A este número se deberá sumar unos 800 docentes que enseñan dicha lengua en todos los niveles educativos. Evidentemente, esta población no representa nada respecto de los 20 millones de cameruneses, y se halla repartida por todas partes en el país.

Aquí, ya no se cuenta con la "seducción de las palabras" (Grijelmo, 2000), ni con su adecuación a las cosas (Foucault, 1968). Ya no se presentan las formas léxicas como depósito de los significados al alcance del homo sapiens, tampoco la lengua como sistema inteligible. Así, habrá que buscarles a la lengua y a las palabras otras naturalezas y funciones. La primera funcionará, ya no como sistema convencional de signos, sino como lenguaje, así como las palabras servirán de formas semióticas, igual que cualquier signo visual. 
De hecho, no es de extrañar que John V. Petrof (1990) vea en las lenguas extranjeras un medio para incrementar la eficacia de la publicidad. En su trabajo, recoge muchas otras ideas, principalmente la de Flavell (1963) y Maddi (1968) según los cuales los individuos obtienen satisfacción en cuanto es nuevo; la de Helson (1959) para quien el uso de la lengua extranjera en la publicidad capta la atención del consumidor; la de Krugman (1988) que sugiere que a medida que el número de anuncios publicitarios aumenta, los individuos pueden ser atraídos por aspectos no ligados a la lógica del mensaje...Se nota que algunos resultados del estudio de Petrof confirman nuestro concepto de publicidad diferida porque la lengua extranjera que juega un papel más icónico que lingüístico produce efectos visuales cuya captación es inmediata por parte del público. La identificación y el reconocimiento de un objeto a partir de la vista funcionan a la velocidad de la luz. En cambio, el significado de una palabra o una frase obedece a un procesamiento psico-cognitivo más o menos rápido, en función de la competencia de la instancia descodificadora.

Sin embargo, teniendo en cuenta la conclusión de Petrof acerca de la intención de compra, podemos afirmar que la publicidad en lengua española es una publicidad a secas y en tiempo real porque la incomprensión de los mensajes viene compensada por la competencia socio-semiótica. Captado por anticipado en virtud de su inmanencia icónico-visual y de su espontaneidad, captado también en función de su inteligibilidad porque apela a la competencia lingüística, todo mensaje publicitario es un discurso potencialmente eficaz. Lo que cuenta más es la sensibilidad del público o de los consumidores, así como su actitud hacia el producto publicitado. Y si la publicidad en lengua extranjera es tan eficiente, cuánto más lo sería si se realizara en un entorno plurilingüe.

\subsection{El multilingüismo como estrategia publicitaria}

El entorno gráfico de Camerún, en el que sobresale la enunciación publicitaria, da cuenta de la situación sociolingüística vigente. Camerún cuenta con casi 300 unidades lingüísticas que se perciben ostensiblemente en el intercambio cotidiano de la gente, en los afiches de todo tipo. Entre los cameruneses tiene lugar, muy a menudo, más que un bilingüismo social generalizado, un multilingüismo que podemos cualificar con toda la razón de identitario. Según Tsofack (2002 : 23), « la publicité est, au Cameroun, un terrain assez typique où se manifeste le plus la plurivocalité qu'impose la situation plurilingue, et qui permet d'observer le plus les pratiques linguistiques caractéristiques des situations diglossiques ». En ese contexto multilingüe las lenguas en presencia no sólo desempeñan la tradicional función comunicativa. Constituyen un instrumento o un argumento más dentro de la gama estratégica de que se sirven los publicistas para persuadir al público.

No como lenguas sino como lenguaje, el multilingüismo que se pone de relieve en los afiches desempeña una función icónica o semiótica en la retórica comercial. Lo que el público capta no es la información transmitida por las diferentes lenguas que cohabitan en el entorno escritural; la atención viene llamada por el efecto singular y esnob que cada código lingüístico causa. Varios fenómenos socio-lingüísticos (fenómenos debidos al contacto de lenguas) contribuyen a dicho efecto, de los cuales 
podemos mencionar la interferencia, la alternancia, la mezcla, la traducción, etc. A ello se puede dedicar un estudio particular, por lo que no lo abordamos de manera detallada en este trabajo. De hecho, nos valemos de la ilustración fotográfica (Fig. 1) para apoyar nuestros propósitos.
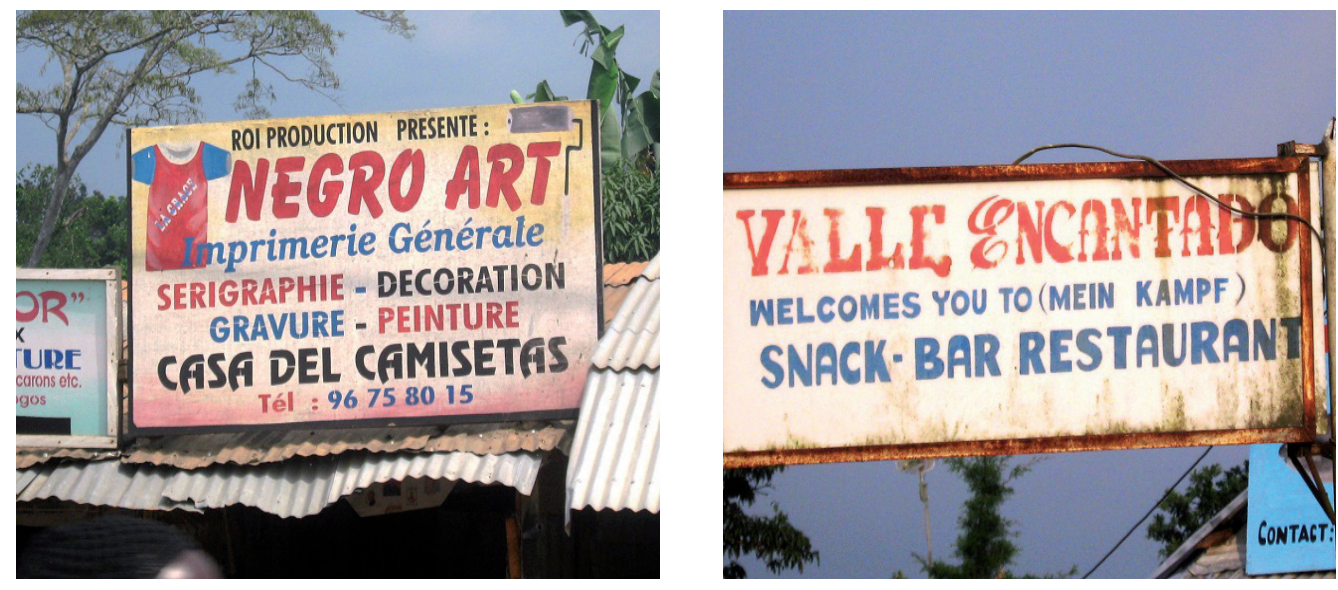

Fig. 1 Anuncios publicitarios multilingües

De las dos imágenes, la primera nos presenta dos enunciados en que cohabitan el francés y el inglés (su sintaxis suena más inglesa que francesa: ROI PRODUCTION PRESENTE: / NEGRO ART). Los enunciados siguientes vienen escritos en francés, y el último en español: CASA DEL CAMISETAS. En el segundo caso, el afiche está encabezado por un enunciado llamativo (color rojo y letra capital) en español: VALLE ENCANTADO. Después, vienen el inglés (WELCOMES YOU TO) y el alemán (MEIN KAMPF). Las dos fotografías han sido sacadas en dos ciudades distintas, la primera francófona (Kyé-Ossi) y la segunda anglófona (Buéa).

En efecto, el multilingüismo constituye en sí una estrategia publicitaria en muchos aspectos. Tal y como afirman Bhatia et al. (2004: 542), « it appears that advertisers worldwide either consciously or unconsciously favor bilingualism over monolingualism ». Por una parte, cada lengua encierra en sí varios valores connotativos que la gente suele representarse ideológicamente o utilizar con diversos fines. En el contexto de Camerún, la multivocalidad de los mensajes publicitarios pone de relieve una realidad plural en que las identidades culturales abundan. A través de los anuncios se pueden leer tanto el pasado - esto es, la historia del país -, como el presente y las aspiraciones hacia el futuro. De hecho, el entorno escritural de las ciudades camerunesas permite repasar algunos acontecimientos históricos. Los escritos en alemán aludirían a la estancia de Alemania en Camerún en cuanto potencia colonial (1884-1918, aproximadamente) y a su legado económico y cultural. Después del Mandato de la SDN (Sociedad de las Naciones), Camerún conoció dos sistemas administrativos, la tutela franco-británica que, a su vez, se refleja como realidad histórica en los escritos urbanos. De Francia 
e Inglaterra se han heredado precisamente las dos lenguas oficiales así como varios rasgos socioculturales. Las demás lenguas y culturas extranjeras como la italiana, la griega, la china, etc. que intervienen en la configuración del espacio urbano tienen su fuente en diferentes y recientes mecanismos institucionales e individuales.

Hablando por ejemplo del inglés, Bonhomme (2003) le atribuye varias funciones en la publicidad suiza, de las cuales retenemos la función internacional que podemos sin ambages aplicar a los mensajes de nuestro corpus. En efecto, una publicidad realizada en inglés confiere a los productos y servicios publicitados el mismo prestigio que tiene la lengua inglesa. De hecho, es evidente que los anuncios multilingües que contienen el inglés proceden de las zonas anglófonas. Pero, en ciertos ámbitos como la electromecánica, la telefonía o la informática, el factor geográfico no restringe el uso del inglés. Y es que estos sectores de la actividad económica (venta de las piezas de recambio, la venta y reparación de la maquinaria, etc.) se hallan casi monopolizados por los anglófonos que sacan provecho del metalenguaje y neoliberalismo anglosajones. En los otros sectores, esto es, la gastronomía, la hostelería, la estética (indumentaria o corporal), etc., todas las lenguas (el inglés, el francés, las lenguas locales) intervienen junto al español.

Al respecto, Teletin y Marques (2008: 453) asocian a dichas lenguas ciertas consideraciones más o menos estereotipadas: «a língua francesa conotada como língua de luxo e de erotismo, a língua castelhana relacionada com o mundo dos sentimentos e a língua italiana essencialmente ligada à comida e mais recentemente à moda ». Este tipo de discurso epilingüístico podría también aplicarse a las lenguas nacionales, y sería para reconocerle a los productos cierto carácter auténtico o identitario. Lo cual participaría también del juego estratégico en la publicidad de la pluralidad lingüística.

\section{Los recursos lingüísticos}

El primer recurso lingüístico que se pone de relieve como táctica publicitaria es el mismo español como lengua, código convencional o conjunto de signos. En efecto, ya es publicidad el hecho de designar una actividad o un establecimiento, fuese comercial o no, en español. A la lengua española como idioma extranjero, preferido a las nacionales y oficiales, se hallan ligadas algunas representaciones. Lengua romántica, lengua musical o exótica, he ahí lo esencial de un discurso epilingüístico susceptible de surtir algunos efectos de índole publicitaria. En la siguiente tabla, presentamos aquellos recursos lingüísticos que participan de la argumentación publicitaria. 


\begin{tabular}{|c|c|}
\hline Recursos lingüísticos & Unidades de análisis \\
\hline \multirow{12}{*}{ Adjetivos valorativos } & Gelateria Moderna \\
\hline & *Buena olor \\
\hline & Dulce sabor \\
\hline & *Cafeteria continental \\
\hline & Buena vista \\
\hline & Restaurant-cabaret *Africana \\
\hline & Restaurant les Merveilles "La Buena Comida" \\
\hline & Estilo femenino \\
\hline & La belleza africana \\
\hline & Dulce noche \\
\hline & Dulce cama \\
\hline & $\begin{array}{l}\text { Farmacia Kyé Ossi de las tres naciones } \\
\text { Centro de Salud con Laboratorio de análisis clínicos de } \\
\text { todo tipo }\end{array}$ \\
\hline \multirow{3}{*}{ Locativos } & Donde Mama Koncha \\
\hline & Aquí se vende cerdo \\
\hline & En vente ici Stihl 070 Aquí se vende Stihl 070 \\
\hline \multirow{2}{*}{ Cuantificadores } & Todo Busness \\
\hline & Trabajo *rapido y muy bien \\
\hline
\end{tabular}

Tabla 1. Recursos lingüísticos con carácter persuasivo

La lengua como código es lo que sitúa los referentes infraestructurales y espaciales del enunciado publicitario por medio de locativos (Donde mama Koncha, Aquí se vende cerdo) y determina sus procedimientos argumentativos mediante los adjetivos valorativos o cuantificadores. En este sentido, se establece entre el emisor y el receptor un contrato comunicativo directo que radica en la competencia lingüística (el contrato indirecto se entabla en virtud de la competencia semiológica). También, el lenguaje articulado selecciona los destinatarios del enunciado publicitario (por ejemplo, sólo los hablantes de esta determinada lengua entienden una publicidad hecha en español), dado que les permite dominar los valores denotativos y connotativos de los elementos léxicos que están en juego en el discurso.

\subsection{Los adjetivos valorativos}

Los procesos de argumentación y de persuasión se funden unos con otros en los discursos publicitarios. A veces, la designación (por medio de los elementos nominales) no es suficiente como para persuadir al público. El recurso a los adjetivos descriptivos, explicativos o valorativos funciona mejor porque con ellos se pueden 
cualificar y comparar los productos que se proponen al público. En nuestro corpus hemos identificado algunos adjetivos que describen o explican valorativamente los productos o servicios puestos al alcance del público. Esta adjetivación positiva expresa los siguientes valores:

- lo bueno ("Buena olor, Buena vista, La buena comida);

- lo dulce (Dulce sabor, Dulce cama, Dulce noche);

- $\quad$ lo femenino (Estilo femenino);

- lo ancho y ajeno (Cafeteria continental, Farmacia Kyé Ossi de las tres naciones);

- lo auténtico (Restaurant-Cabaret *Afrikana, La belleza africana, Salon de coiffure africana);

- $\quad$ lo moderno (*Gelateria moderna)

Estos adjetivos atribuyen propiedades a los nombres que modifican, los cuales, en los ejemplos mencionados, se refieren al mundo doméstico o a la vida socioeconómica y encierran un carácter positivo (el olor, la vista, el sabor, la cama, la noche, el estilo, el café, la farmacia, el restaurante, la belleza, etc.).

\subsection{Los cuantificadores}

Según Robles Ávila (2005: 265) existe en la publicidad una tendencia manifiesta al empleo de los cuantificadores universales, especialmente "todo", el cuantificador ponderativo por excelencia. Todo Busness es el único ejemplo que nos brinda el corpus. Pero, además, del grupo de los cuantificadores no universales destacamos la forma apocopada de "mucho" el caso ... Muy bien. Aquí, "todo busness" conlleva la idea de lo global, de lo general, y significaría "comercio general". Si el establecimiento que lleva este mensaje publicitario lo vende todo o casi todo, lo que es cuantificar el producto o el servicio, la secuencia "muy bien" de ... trabajo *rapido y muy bien expresa una cuantificación cualitativa, esto es, que recae en la calidad del trabajo o servicio rendido al público.

\subsection{Los locativos espaciales}

Cifuentes Honrubia (1989 : 251) define los locativos espaciales como un conjunto de «unidades funcionales que agrupa bajo la dimensión espacial tanto a elementos deícticos como inherentes y no deícticos, categorizados por las tradicionales funciones de preposición y adverbio (e incluso sufijos y locuciones preposicionales)». Trátese de los locativos situacionales o direccionales, su papel es informar del lugar en que se encuentran o se sitúan los objetos. Esta relación entre lengua y espacio se traduce de diversas maneras en las estructuras lingüísticas. Desde el punto de vista epistemológico, varias disciplinas se ocupan de dicha relación, la filosofía del lenguaje, la pragmática, la lingüística, etc.

Ya en la orientación lógica de la filosofía tradicional y la lógica clásica de fines del siglo XIX y principios del XX, el valor existencial ha sido asociado a ciertos términos. Por ejemplo, la clasificación semántica de los verbos distingue los llamados verbos existenciales; existir, ser, estar, haber, etc. son algunos de ellos. A partir del tratado sobre las categorías de Aristóteles, se pueden distinguir predicaciones esenciales de 
las accidentales. Por eso, en las formas soy, estoy, doy, voy, hay, etc. de los verbos ser, estar, dar, ir y haber, se puede identificar el locativo latino ibi que tenía un valor espacio-temporal. Predicar con estos verbos, especialmente en presente de indicativo significa expresar el hic et nunc (aquí y ahora) de la enunciación, a la par que se afirma su valor existencial. De hecho, decir Soy significa que se es o se existe en un momento y un lugar dados.

De igual modo, el adverbio "aquí" que aparece dos veces en el corpus (Aquí se vende...) traduce la citada relación entre la lengua y el espacio. Junto con el adverbio "donde" (Donde Mama Koncha), constituyen un procedimiento muy persuasivo en los discursos publicitarios. Por lo menos, "aquí" y "donde" desempeñan un papel deícticoreferencial (deíxis ad oculos el uno y deíxis anafórica el otro), así como actúan casi de acto de habla performativo ante los destinatarios. En la tabla 1 se recapitulan todos estos recursos lingüísticos.

En lo que llevamos visto hasta el momento, hemos tratado de abordar la primera vertiente instrumental de todo mensaje publicitario. En efecto, el abordaje lingüístico de todo discurso en general y del discurso publicitario en particular no desvela sino en parte su carga semántica. Y es que en publicidad se barajan mucho más recursos que los puramente lingüísticos.

\section{Los recursos metalingüísticos o semióticos}

No es suficiente la competencia lingüística para entender un mensaje publicitario, se necesitan otras competencias tales como la pragmática, sobre todo la semiótica. Ésta es, en palabras de Eduardo Serrano Orejuela (2007 : 42), «la articulación jerarquizada de las competencias discursiva, semiolingüística, textual y semántica, operante durante la generación y la interpretación (que es, ella también, generación) de textos concretos verbales y no verbales». En efecto, existen mensajes que sólo se descifran o descodifican gracias a las predisposiciones cognitivas o culturales de que disponen los destinatarios. Entonces, se tratará aquí de la llamada competencia interpretativa, ya que, según dice Umberto Eco (1992 : 285), citando a Morris, « algo es un signo si, y sólo si, algún intérprete lo considera signo de algo. La semiótica, por tanto, no se ocupa del estudio de un tipo de objeto particular, sino del estudio de los objetos ordinarios en la medida en que (y sólo en la medida en que) participan en la semiosis ». A continuación, mencionamos tres elementos que, aunque no pertenecen al signo lingüístico como tal, conllevan elevado potencial significativo.

\subsection{La tipografía}

Dado que lo tipográfico no es completamente ajeno a lo lingüístico (la ortografía, la fonética o la fonología se ocupan también del componente gráfico del lenguaje), tenemos que evidenciar el estatuto semiológico del objeto sobre el que actúa la tipografía. A este respecto, subrayemos que la tipografía puede efectivamente abordarse desde el prisma de la semiótica visual o de la imagen. El presente abordaje puede enmarcarse en lo que Juan Magariños de Morentin (2002) califica de semiosis visual ${ }^{1}$, que según él, es objeto de dos preguntas de base: lo que se muestra y cómo se lo muestra. En otra

${ }^{1}$ El mismo autor distingue también el semiosis verbal y el semiosis indicial. 
ocasión Magariños de Morentin considera al signo objeto de la percepción visual como "imagen material visual" y lo define (desde el enfoque de la semiótica de la imagen visual) como «una propuesta de percepción visual, considerada como representación, destinada a la configuración de una forma, para su valoración por el perceptor». Pérez Peña (2010 : 12) comparte esta concepción:

Reconocer la tipografía desde el diseño gráfico y la semiótica permite identificar la importancia que reviste este elemento en dos áreas de estudio diferentes. Estas áreas, aunque parecieran estar a una gran distancia la una de la otra, terminan por entrelazar sus planteamientos para dar cuenta que en la tipografía subyacen factores visuales que, además de permitir un proceso de lectura a partir de sus cualidades visuales, generan estados emocionales y permiten la asunción de valores que de cierta forma favorecen la interpretación de un texto.

Sin embargo, el enfoque semiótico de la tipografía constituirá para nosotros un trampolín o un medio destinado a analizar mejor los mensajes publicitarios. Según Michael S. McCarthy y David L. Mothersbaugh (2002 : 67), « la typographie est un élément majeur dans toute publicité essentiellement axée sur les mots, et a le potentiel d'influencer significativement la motivation, l'opportunité et la capacité à traiter les messages publicitaires ». En efecto, el escrito se materializa en unos trazos -las letrascuyo aspecto visible, además del significado convencional, puede aportar un significado extralingüístico gracias a su capacidad figurativa, ya que va a ser precisamente en la sustancia - en la visualidad - en la que el código escrito publicitario va a basar toda su estrategia.

De hecho, estudiar semióticamente los recursos tipográficos de los mensajes publicitarios consistirá en nuestro caso en describir las maneras como los trazos o letras se forman y disponen en los carteles. También será preciso demostrar cómo el diseño de esas formas actúa y constituye un instrumento persuasivo dentro de la trama argumentativa del discurso publicitario.

Podemos describir algunas de las formas tipográficas con que cuenta nuestro corpus en base a cuatro perspectivas esenciales, que son la dimensión, la posición, la orientación y el fondo. Por lo demás, nos parece pertinente dar cierta importancia al soporte (sobre todo a su forma) de los distintos motivos tipográficos, ya que constituye un valor agregado a la significación de los mismos. Souchier (2006: 70) afirma que « la typographie est $[\ldots]$ ontologiquement liée à l'écriture en ce qu'elle la donne à lire, la révèle à son tour. Elle en est l'empreinte, l'image, le double industriel qui s'en est peu à peu affranchi. S'intéresser à la question de la signification de la typographie, c'est donc fatalement revenir à l'histoire de l'écriture et réinterroger sa fonction autant que sa constitution. Historiquement, le terme est attesté en 1554 (typographe), il entérine l'industrialisation de l'écriture ».

Esta aserción procedente de un artículo publicado en Cahiers GUTenberg demuestra la concepción maquinista de la tipografía, como si la escritura no tuviera ninguna historia antes del descubrimiento de la imprenta en 1492. En parte, la ilustración (de la Fig. 2) se caracteriza porque recuerda aquella orientación industrial de la tipografía: letras sueltas y rectas, mayúsculas, disposición horizontal (de izquierda a derecha) del 
soporte, etc. El fondo rojo o rojizo de la imagen hace más visibles y legibles los trazos por un lado y los enunciados por otro. Estos últimos han sido diseñados con una tinta blanca, el color que mayor sensibilidad posee frente a la luz y a la vista. Por lo demás, los enunciados AFRICANA y EL PALACIO HOTEL se perciben desde la posición frontal del observador.
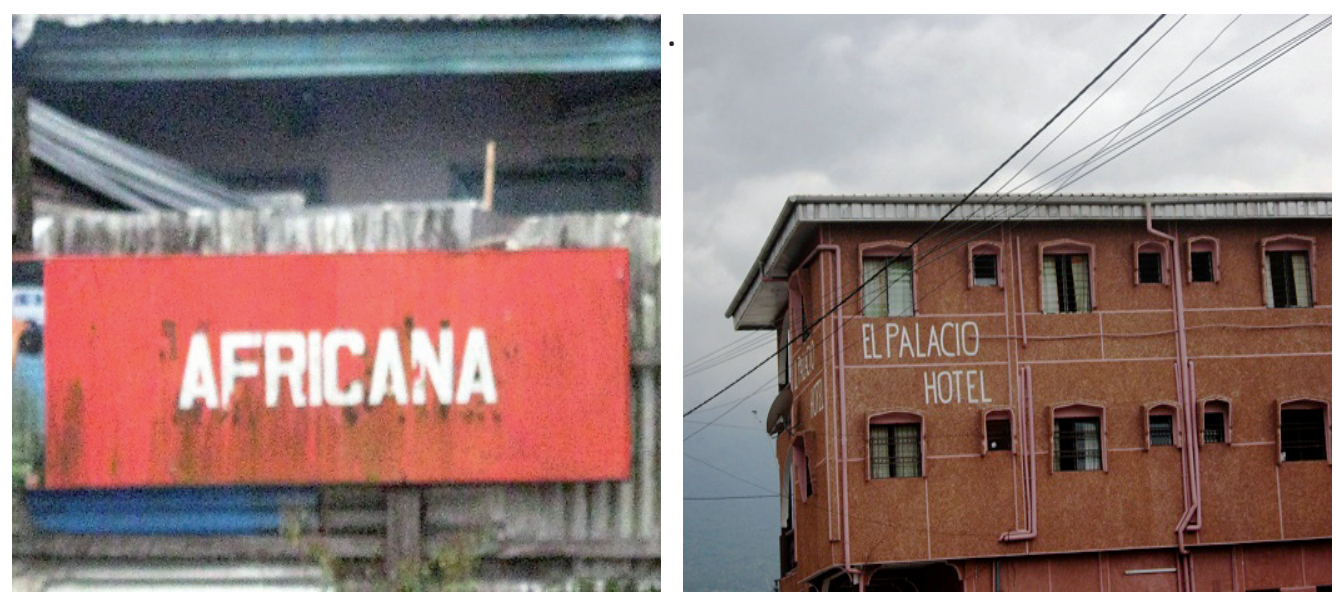

Fig. 2 Tipografía maquinista

En la ilustración (de la Fig. 3) los tres enunciados no ocupan la misma posición en el soporte. El primero, BAR-RESTAURANTE, forma un arco de círculo o una bóveda hemisférica cuyo dorso se halla orientado hacia arriba, mientras que los dos últimos (DONDE y MAMA KONCHA) forman dos líneas horizontales. El conjunto constituye una cúpula que encuadra un plato de pollo, como si las letras constituyeran un trazo continuo para dibujar. La disposición de las letras obedece al aspecto general del medio-círculo y presenta motivos cuyos efectos visuales resaltan gracias a los recursos cromáticos basados en el color rojo de las grafías y el azul del soporte. Asimismo, los enunciados, y la forma geométrica que resulta, se hallan en un plano oblicuo izquierdaderecha y no frontal a causa de la colocación del soporte en el espacio físico. El conjunto puede asimilarse a un cubierto transparente cuyo contenido no es sino el pollo que se divisa en el centro. Si los enunciados DONDE y MAMA KONCHA pueden constituir el fondo y la base del utensilio, BAR-RESTAURANTE será una cúpula protectora de la comida. Todo ello informa sobre las condiciones (de limpieza y sanidad) del restaurante. 


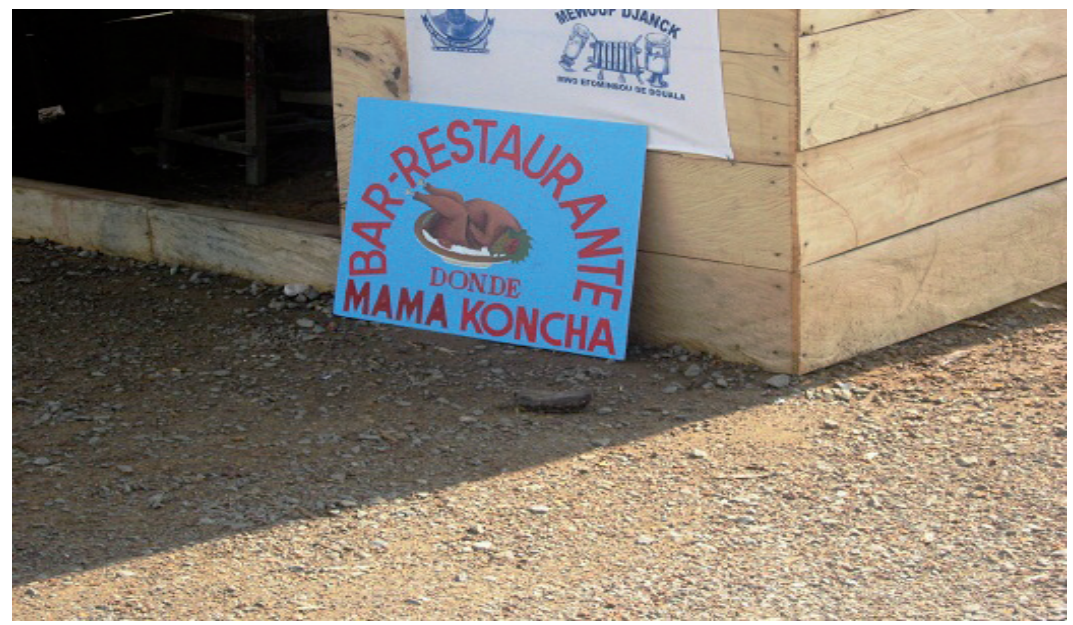

Fig. 3 Escritos en forma geométrica

En cuanto a las formas tipográficas de la ilustración (Fig. 4), pese a un fondo algo oscuro, ostentan unos trazos caligráficos. La cursiva y la regularidad de los motivos compensan la calidad cromática y acrecientan las características estéticas de la escritura publicitaria. El uso de la cursiva y el carácter caligráfico humanizan la escritura.
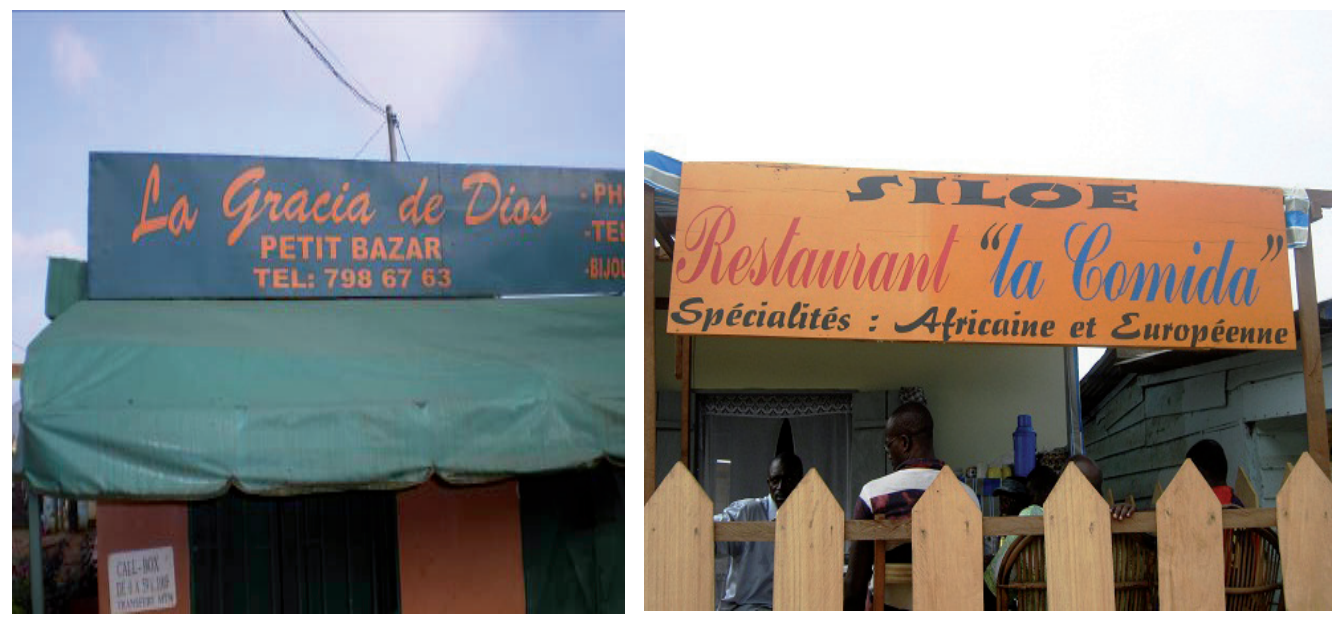

Fig. 4 Escritura caligráfica y antropo-centrada

En las referidas imágenes fotográficas se concibe la tipografía en su dimensión lingüística y sensorial, lo cual permite reconocer el alto valor comunicativo que manifiestan sus características visuales. Estas últimas, al funcionar como manifestación del mensaje lingüístico, establecen una relación de correspondencia, entre significante y significado, entre forma y contenido, dando cuenta del valor publicitario que 
manifestaría lo plástico. Además, las letras o palabras de ciertos anuncios publicitarios se iconizan levemente ya sea a partir de su forma, ya mediante su disposición en el espacio del soporte. Garrido Lora (1995) habla del iconosimbolismo que, en cuanto es un recurso publicitario, presenta varias características visuales y comunicativas.

\subsection{Las coordenadas situacionales}

En ciertos carteles publicitarios, las letras (las palabras) coexisten con las cifras. Igual que los recursos orto-pictográficos y cromáticos, los elementos numéricos desempeñan un papel importante. Generalmente, son coordenadas postales y telefónicas que informan de la ubicación de la institución comercial o no comercial de la que se hace publicidad. Esas referencias numéricas tienen dos objetivos. Por una parte, responden a una exigencia administrativa. En efecto, cada institución social o económica tiene una identidad que le confiere su propietario bajo el poder jurídico de la administración. En el recibo de declaración o de apertura que firma la autoridad administrativa, resaltan generalmente la denominación, el estatuto jurídico y la dirección. La dirección puede constar de la sede social, del apartado correos, del número de teléfono, del sitio web y de la dirección electrónica. Todo o parte de estos elementos puede figurar en la valla publicitaria. Se, comprueba tras observar el corpus, que las formalidades administrativas arriba mencionadas no siempre se respetan. Además, parece que muchos carteles hacen referencia a empresas que forman parte del sector informal. De hecho, la coordenada más frecuente es el número de teléfono. Viene, en segundo lugar, el apartado de correos que, por lo general, no es fácil atribuirse. Multitud de imágenes de nuestro corpus ejemplifican lo dicho.

Por otra parte, las coordenadas numéricas constituyen en sí una técnica publicitaria porque sirven para dar más informaciones sobre el producto o la empresa. Un número de teléfono o dos -según que el propietario de la empresa se haya afiliado a uno de los dos principales operadores telefónicos o a los dos (Orange y MTN) -, además de eso, un apartado de correos..., todo ello orienta suficientemente al usuario o potencial cliente. La quinta ilustración es bastante ilustrativa dado que presenta varias informaciones que sirven para localizar la empresa: el apartado de correos (BP 361 YDE); el teléfono (TEL 91076 78); la dirección electrónica (E-MAIL: lafiesta@yahoo. fr); el barrio (EFOULAN PONT); la circunscripción administrativa (YAOUNDE 3e). Las más de las veces, lo que figura es el número del móvil, no el teléfono fijo, tal vez con la intención de personalizar la empresa. De este modo, se crea entre el producto o la empresa y el público una relación directa, así como se consigue la eficiencia o rendimiento comunicativo del mensaje gráfico publicitario (Martínez Bouza, 2010 : 25). 

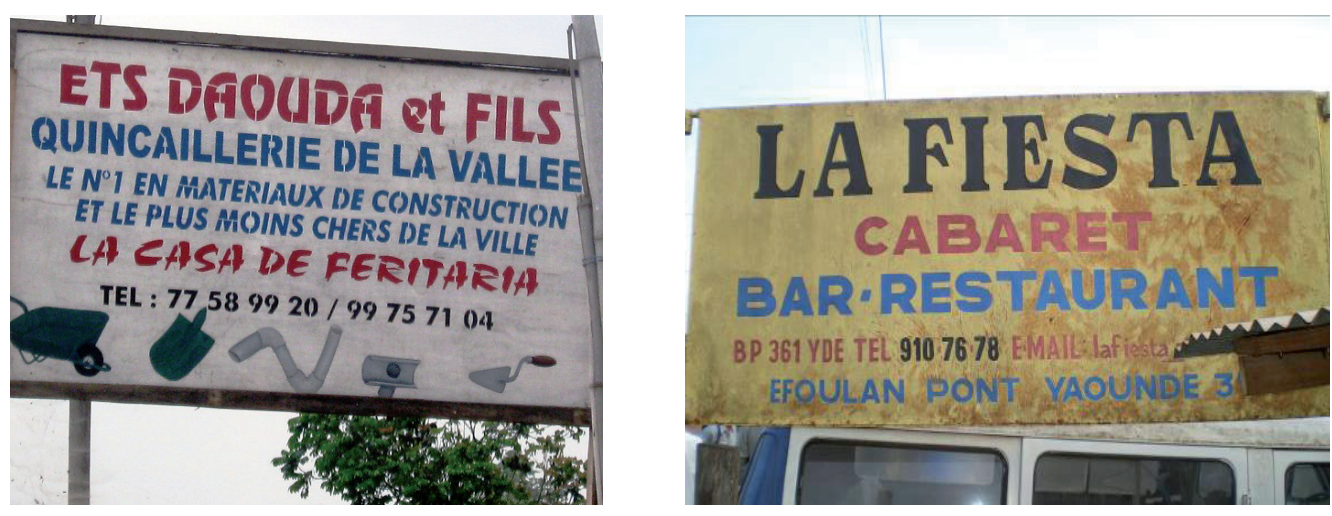

Fig. 5 Anuncios con coordenadas situacionales

Como conclusión, cabe mencionar que la inscripción espacial de mensajes ha vuelto a ser una de aquellas prácticas que participan de la llamada cultura urbana. Dicha cultura es, de por sí, un fenómeno esencialmente polifónico o dialógico (Bajtín, 1978; Lamizet, 2007). En base a diversas motivaciones - el español como lengua extranjera en Camerún, la cercanía de Guinea Ecuatorial, el fútbol (Eto'o Fils que ha conectado España con Camerún), las telenovelas, etc. - la lengua española ha ocupado un lugar preponderante en el concierto de dicha cultura diversificada y de una publicidad plurivocal (Tsofack, 2002). Su estatuto de lengua extranjera constituye en sí una estrategia persuasiva dentro de la comunicación publicitaria. El fenómeno del multilingüismo es igualmente una técnica publicitaria no menos pertinente. Y para explorar todas las posibilidades publicitarias que giran en torno a la lengua española, hemos echado mano de diversos recursos tanto lingüísticos como extralingüísticos como objeto de análisis, postulando así que un estudio exclusivamente lingüístico no basta para explotar todas las riquezas de un discurso publicitario. El recurso a las disciplinas afines a ésta, la semiótica y la pragmática, o las ciencias del lenguaje en general, sería provechoso a este propósito.

\section{Bibliografía}

Amparo Alcina, C. Ma (1999): Las expresiones referenciales. Estudio semántico del sintagma nominal, Tesis doctoral, Universidad de Valencia.

Bajtin, M. (1978): Teoría y estética de la novela, Taurus, Madrid.

Bonhomme, M. (2003) : «Les fonctions de l'anglais dans la publicité suisse», Bulletin suisse de linguistique appliquée, 77, 1-16.

Cifuentes Honrubia, J. L. (1989): Lengua y espacio. Introducción al problema de la deíxis en español, Alicante, Espagrafic.

Eco, U. (1990): Los límites de la interpretación, Barcelona, Lumen.

FERnandez Fernandez, P. (2010): «Las palabras en la publicidad», Revista Comunicación y Hombre, 6, 287-288.

Foucault, M. (1968): Las palabras y las cosas: una arqueología de las ciencias humanas, Buenos Aires, Siglo XXI Editores. 
GARRIDO LoRA, M. (1995): «El iconosimbolismo de la imagen publicitaria», Questiones publicitarias, 4, 73-80.

GriJelmo, A. (2000): La seducción de las palabras, Madrid, Santillana Ediciones.

Groupe M. (1992): Tratado del signo visual, Madrid, Cátedra.

Gutiérrez Araus, M ${ }^{\mathrm{a}}$ L. et alii. (2005): Introducción a la lengua española, Madrid, Ramón Areces.

HÉBERT, L. (2011) : Dictionnaire de sémiotique générale, Rimouski, Université du Québec à Rimouski.

JAKOBSON, R. (1963): Ensayos de lingüistica general, Barcelona, Planeta-Agostini.

Khalef, E. D. (2011): «De la sémiotique du discours publicitaire», Synergie, 14, $97-$ 104.

Lamizet, B., 2007 : «La polyphonie urbaine : essai de définition», Communication et organisation [en línea], 32 | 2007, http://communicationorganisation.revues. org/1141.

Martínez Bouza, J. M. (2010): La influencia del Aspecto en la eficiencia del mensaje gráfico publicitario, Barcelona, Universidad Autónoma de Barcelona.

McCARThy, M. S. \& Mothersbaugh, D. L. (2002) : «Les effets de la typographie sur la persuasion publicitaire : un modèle général et des tests empiriques préliminaires», Recherche et Applications en Marketing, 17 (4), 67-89.

Magariños de Morentín, J. (2001). «La(s) semiótica(s) de la imagen visual», Cuadernos, 17, 295-320.

------- (2002): «Hacia una semiótica indicial. Acerca de la interpretación de los objetos y los comportamientos». [en línea: 09 / 2002], www.centro-de-semiotica.com.ar/ Semiotica-Indicial.html.

Pérez Peña, N. C. (2010): «Apuntes sobre semiótica en tipografía», Revista S, 4, 11 27.

Petrof, J. V. (1990) : «L'utilisation des langues étrangères comme moyen d'augmenter l'efficacité de la publicité : une approche expérimentale», Recherche et Applications en Marketing, 5 (2), 1-16.

Rey Fuentes, J. (1997): «El iconismo gráfico en la escritura publicitaria», Questiones publicitarias, 6, 9-39.

Robles Ávila, S. (2005): «La ponderación en el discurso publicitario», RILCE, 21, 263-280.

Serrano Orejuela, E. (2007): «Competencia semiótica con soneto», Revista Habladurías, 6, 37-46.

SOUCHIER, E. (2006) : «Quelques remarques sur le sens et la servitude de la typographie. Pratiques, discours et imaginaires», Cahiers Gutenberg, 46-47, 69-98.

Teletin, A. \& Marques, I. S. (2008): «Multilinguismo em anúncios publicitários portugueses: recursos linguísticos, funções e valores», $A P L$, XXIII, 451-461.

Tsofack, J-B. (2002). «Publicité, langue et plurivocalité au Cameroun», SudLangues, $1,22-36$.

UMBerto, E. (1992) : Los límites de la interpretación, Barcelona, Lumen. 